\title{
Negócios processuais em contratos empresariais: uma forma de redução de custos de transação
}

Procedural agreements in business contracts: a way to reduce transaction costs

\author{
Marcus Paulo Röder \\ Universidade Federal do Paraná, Curitiba, Paraná, Brasil \\ Kirstin Elise Richter Vieira \\ Universidade Federal do Paraná, Curitiba, Paraná, Brasil
}

\begin{abstract}
Resumo: O artigo sustenta a existência de um habitat possível e pertinente para a celebração de negócios jurídicos processuais (especialmente os ditos atípicos e permitidos a partir da cláusula aberta do art. 190 do Código de Processo Civil de 2015): os contratos empresariais, em razão das suas características e peculiaridades. Em seguida, valendo-se dos pressupostos da Análise Econômica do Direito, apresentam-se argumentos pelos quais as partes contratantes, inseridas no contexto específico de contratos empresariais, podem se valer dos negócios jurídicos processuais com o objetivo de racionalização do processo, de aumento da eficiência processual e, consequentemente, de redução de custos de transação.
\end{abstract}

Palavras-chave: Contratos empresariais; Negócios Jurídicos Processuais; e Custos de Transação.

\begin{abstract}
This paper aims to support the existence of a possible and pertinent habitat for the conclusion of procedural agreements (especially the atypical sayings and allowed by the open clause of art. 190 of the Code of Civil Procedure of 2015): the business contracts due to their characteristics and peculiarities. Then, based on the assumptions of the Law and Economics, arguments are presented whereby the contracting parties, inserted in the specific context of business contracts, can use the procedural agreements with the objective of streamlining the process, increasing procedural efficiency and, consequently, reduce transaction costs.
\end{abstract}

Keywords: Business contracts; procedural agreements; Transaction Costs. 
Sumário: Introdução. 1. Análise Econômica do Direito e a Economia dos Custos de Transação. 2. Negócios Jurídicos Processuais. 3. Negócios processuais e eficiência processual. Conclusão. Referências.

\section{Introdução}

É objetivo deste artigo a realização de ensaio sobre as possibilidades de se pensar os negócios jurídicos processuais como instrumentos de redução de custos de transação em contratos empresariais.

Não se pretende, por certo, exaurir as possibilidades de análise que decorem desse tema. O que se pretende, diversamente, é efetuar recorte que, atentando para pressupostos principiológicos e teóricos do direito contratual, permitam apontar para o diálogo possível com a análise econômica do direito, culminando com possíveis exemplos desse diálogo.

Ainda que se reconheça que a arbitragem pode ser uma via eficiente para a solução da questão atinente à redução de custos de transação nos litígios empresariais (AGUSTINHO; CRUZ, 2014), é certo que, sob a égide da jurisdição estatal, o Código de Processo Civil de 2015 (Lei 13.105/2015, doravante apenas CPC/15) também passa a oferecer uma alternativa.

Não se pretende, aqui, investigar qual seria a escolha mais eficiente entre arbitragem e jurisdição estatal, mas, sim, partir desta e investigar se e como o negócio jurídico processual ${ }^{1}$ pode ensejar o incremento da eficiência econômica dos contratos em que tais negócios venham a ser inseridos.

Afinal, mesmo que a jurisdição estatal seja a via ordinária (no sentido de ser a mais comum e usual na prática), ao fim e ao cabo, resta somente às partes definirem qual a maneira pela qual pretendem resolver suas

\footnotetext{
1 Desde logo é importante fazer uma observação metodológica quanto à nomenclatura adotada. Para tanto, vale uma rápida explicação quanto ao uso genérico do termo negócios jurídicos processuais. "A rigor, os negócios jurídicos processuais podem ser atos bilaterais ou unilaterais. O negócio processual unilateral é expressão de vontade de um único sujeito (ou polo de sujeitos), que unilateralmente dispõe de alguma posição jurídica processual de que era titular. O negócio processual bilateral é fruto do ajuste de vontade de dois ou mais sujeitos (ou polos de sujeitos), que coordenadamente dispõem sobre suas respectivas posições processuais. Os negócios jurídicos bilaterais são também chamados de convenções processuais. Na linguagem corrente, aliás, muitos autores têm aludido genericamente a negócios processuais tendo em vista, precisamente, os negócios bilaterais (convenções) processuais" (TALAMINI, 2015, p. 2).
} 
controvérsias, a depender do que julgarem mais adequado e eficiente (TARUFFO, 2009).

A razão pela qual se defende o presente estudo em torno dos contratos empresariais é que a relação jurídica estabelecida entre empresários $^{2}$ possui uma lógica própria e especial que deve ser interpretada de uma forma diferenciada das demais relações civis. ${ }^{3}$ Dessa forma, buscar-se-á abordar o tema proposto sobre a perspectiva exclusiva do contexto dos contratos empresariais, visto que seu cenário de incidência desponta enquanto um habitat para celebração de negócios jurídicos que visam a flexibilização das normas processuais de modo a melhor adequálos à solução do caso concreto e, consequentemente, reduzir custos.

Invariavelmente, litígios envolvendo contratos empresariais chegam ao Poder Judiciário e necessariamente precisam ser julgados de forma coerente e adequada. Além disso, o Judiciário também possui um papel institucional e fundamental na formação de precedentes que norteiam e informam os contratantes (e também os futuros julgadores - sejam juízes ou árbitros) quando da negociação, redação e interpretação dos contratos; e em razão dos impactos econômicos, cada vez mais não se admitem decisões arbitrárias ou divergentes (conflitantes ou até mesmo contraditórias) e se exige um maior refinamento e compreensão dos elementos técnicos por parte do Poder Judiciário, visando à necessidade de segurança jurídica e previsibilidade para calcular os fatores que

\footnotetext{
${ }^{2}$ As relações estabelecidas entre empresas costumam ser denominadas, principalmente no comércio eletrônico, pela expressão em inglês business-to-business ("de empresa para empresa"), identificada pela sigla B2B, em contraste com a expressão business-to-commerce (“da empresa para o comércio"), cuja a sigla é B2C, como sendo a transação comercial entre empresas e o consumidor. A distinção é interessante exatamente porque é feita partindo da premissa que nas relações entre empresas (B2B) há um poder de negociação equivalente (pois geralmente há profissionais com domínio jurídico assessorando a contratação). Por outro lado, nas relações com o consumidor (B2C), há uma grande assimetria de informação quanto ao conteúdo do negócio celebrado.

${ }^{3}$ Nesse sentido, RIBEIRO e GALESKI JÚNIOR (2009, p. 14) lecionam: “O empresário lança mão de inúmeras obrigações, operando no sistema de constituição de negócios jurídicos indispensáveis à prática econômica. Negócios que são identificáveis na escolha e aquisição da matéria prima, na escolha e contratação de empregados e prestadores de serviço, na escolha dos parceiros e no transpasse dos produtos e serviços aos consumidores. Na instrumentalização destes negócios despontam os contratos, especialmente aqueles relacionados à vinculação dos empresários entre si, seja na compra e venda de insumos, ou no estabelecimento de uma parceria. Tais contratos indissociáveis da prática empresarial, associados à figura do empresário, para permanecerem compatibilizados com a especialidade de a quem são destinados, precisam igualmente ser tratados de forma especial".
} 
influenciam a tomada de decisóes e a racionalidade dos agentes privados (KLEIN, 2013, p. 17-19).

A partir desses argumentos, torna-se evidente que o Poder Judiciário também deve estar preparado para lidar com o aparecimento de convenções processuais em contratos empresariais.

Em razão do advento do CPC/15, que para além de adotar um modelo cooperativo de processo (OLIVEIRA, 2003; MITIDIERO, 2015), traz diversas normas que prestigiam a autonomia da vontade, permitindo que as partes negociem sobre o processo, de modo mais evidente do que no CPC/73 (Lei 5.869/1973), inclusive, com a inserção de uma cláusula geral que autoriza a pactuação de negócios processuais atípicos (CABRAL, 2016; CUNHA, 2016).

Verifica-se, no entanto, que historicamente há uma enorme relutância por parte de alguns doutrinadores ${ }^{4}$ acerca da possibilidade de celebração de contratos com convenções processuais sob o argumento de que isso representaria uma (re)privatização do processo civil. Este ensaio, por sua vez, buscará refutar essas críticas na tentativa de demonstrar que é sim possível a celebração de convenções processuais, sem que isso represente um risco ou uma ameaça ao direito processual civil.

É necessário comemorar o movimento de fortalecimento de um modelo cooperativo de processo adotado pelo CPC/15, que permite superar o equivocado receio de que a publicização do processo não poderia conviver com a autonomia privada (GODINHO, 2015).

Assim se faz necessário defender a superação da dicotomia maniqueísta que pouco contribui para a compreensão responsável do tema, pois, de forma defasada, tem como pressuposto uma suposta incompatibilidade entre ordem pública e (a já não mais possível) visão privatista do liberalismo clássico dos séculos XVIII e XIX. Afinal, adotando-se a perspectiva civil-constitucional, é evidente que não é possível

\footnotetext{
${ }^{4}$ São vários os doutrinadores brasileiros que apresentam opiniões contrárias à existência de negócios jurídicos processuais, tais como Cândido Dinamarco, Daniel Mitidiero, Vicente Greco Filho, Calmon de Passos etc. LEONARDO CUNHA (2016, p. 48) sintetiza essas críticas da seguinte forma: "Em suma, as opiniões contrárias à existência dos negócios jurídicos processuais partem do pressuposto de que somente há negócio jurídico se os efeitos produzidos decorrem direta e expressamente da vontade das partes, o que não ocorreria no processo, ou porque os efeitos decorrem da lei, ou porque seria necessária a intervenção processual para que se produzam”.
} 
celebrar negócios jurídicos com a intenção de violar as bases do devido processo constitucional, do Estado Democrático de Direito e afrontar direitos fundamentais.

Portanto, com o presente estudo pretende-se compreender os pressupostos (objetivos e subjetivos) e os requisitos específicos para celebração de negócios jurídicos processuais.

Por fim, será explorado o interesse da ciência econômica pelo fenômeno contratual e, nos valendo dos instrumentos e pressupostos da Análise Econômica do Direito, intentaremos uma abordagem interdisciplinar para fundamentar o raciocínio de que a inserção de convenções processuais em contratos pode servir para redução de custos e, consequentemente, estruturar uma regência jurídica mais eficiente e previsível. Para tanto, será necessário um breve estudo da Teoria Econômica do Contrato, sob a perspectiva da Nova Economia Institucional, com a finalidade específica de se valer dos contributos da Teoria dos Custos de Transação.

\section{Análise Econômica do Direito e a Teoria dos Custos de Transa- ção}

A Análise Econômica do Direito (AED) nada mais é do que a aplicação do instrumental analítico e empírico da economia, para se tentar compreender, explicar e prever as implicações fáticas do ordenamento jurídico (GICO JR, 2012, p. 14).

Não nos é muito relevante, para a finalidade deste ensaio, realizar um estudo minucioso acerca do histórico do movimento de aproximação entre o Direito e a Economia. Nos basta apenas compreender que "a Análise Econômica do Direito é essencialmente um movimento interdisciplinar, que traz para o sistema jurídico as influências da ciência social econômica, especialmente os elementos valor, utilidade e eficiência" (RIBEIRO; GALESKI JÚNIOR, 2009, p. 69).

No que se refere aos contratos, a AED atenta não apenas para a questão da formação dos contratos, mas também para determinar quais pactos merecem proteção e quais as consequências do seu descumprimento, assim como questões acerca da melhor consecução das 
avenças, diante de lacunas e falhas de mercado e em análise do papel dos Tribunais (RIBEIRO; GALESKI JÚNIOR, 2009, p. 129-130; FERNANDO ARAÚJO, 2007, p. 17).

Considerando o tema deste trabalho, interessa-nos aqui tão somente assimilar o conceito de custos de transação a fim de compreender a relevância da inserção de negócios jurídicos processuais em contratos empresariais.

Os custos de transação são objeto da Nova Economia Institucional (NEI), escola capitaneada por Oliver Williamson e Douglas North, a partir dos escritos de Ronald Coase ${ }^{5}$, que tem como premissas orientadoras: (i) as instituições ${ }^{6}$ são importantes para a análise econômica; (ii) a determinação dessas instituições pode ser compreendida e explicada por meio do instrumental da teoria econômica; (iii) as instituições afetam o desempenho econômico de maneira sistemática e preditiva (RIBEIRO; AGUSTINHO, 2011, p. 124).

Ainda, a NEI possui como princípios fundamentais: i) a assunção de que os indivíduos seguem o auto interesse consoante à sua racionalidade, a qual está sujeita a limitações mais numerosas do que aquelas assumidas pelos neoclássicos ${ }^{7}$; e ii) os indivíduos buscam a maximização da riqueza, cuja concepção consiste na persecução de estruturas institucionais que aprimorem a capacidade de produção da sociedade (RIBEIRO; AGUSTINHO, 2011, p. 125).

Partindo das premissas e princípios que regem a NEI, encontra-se a Teoria da Economia dos Custos de Transação (ECT), cuja principal crítica se dirige aos pressupostos da teoria neoclássica e a presunção de perfeição

\footnotetext{
${ }^{5}$ A origem da NEI remonta ao artigo seminal de Ronald Coase, The Nature of the Firm de 1973, mas o uso do termo, de modo a designar uma proposta autônoma de teoria econômica, é atribuído a Oliver Williamson, no seu livro Markets and Hierarchies de 1975. Cf. KLEIN, 2016, p. 129-143.

${ }^{6}$ As instituições representam, genericamente, as "regras do jogo", e estabelecem um complexo de ações possíveis que devem ser consideradas como parte de um sistema, e que compõe o sistema formal de instituições, quando incorporadas pelo direito, e o informal, na hipótese de não incorporação (RIBEIRO; GALESKI JÚNIOR, 2009, p. 186).

${ }^{7} \mathrm{O}$ pensamento econômico chegou a admitir que as condutas humanas seriam norteadas por uma racionalidade econômica absoluta. Segundo essa visão, (dita "econômica neoclássica"), a decisão individual decorreria de uma ponderação intelectual sobre os benefícios e as desvantagens envolvidos numa situação concreta. Logo, sempre prevaleceria a escolha pela alternativa mais vantajosa.
} 
do mercado. Para a teoria neoclássica, o mercado encontraria o perfeito equilíbrio entre oferta e demanda, não se concedendo relevância para as variáveis relacionadas ao custo de se negociar ou fazer cumprir acordos. Ocorre que em relações reais de mercado, tais custos são sempre presentes e influem diretamente na interação entre os agentes econômicos (RIBEIRO; GALESKI, 2009, p. 105).

Exatamente por adotar como premissa a racionalidade limitada (bounded rationality) e considerar o oportunismo das partes que a ECT não ignora a existência dos custos de transação (KLEIN, 2013, p. 143). Neste sentido, ZYLBERSTAJN e STAJN (2005, p. 8-9), ao tratarem da contribuição de Williamson, explicam que:

O conceito básico da ECT é que existem problemas futuros potenciais nos contratos, problemas esses que são antecipados pelos agentes que desenham os arranjos institucionais no presente. Os agentes podem descumprir promessas, motivados pelo oportunismo e pela possibilidade de apropriação de valor dos investimentos de ativos específicos. Na impossibilidade de desenhar contratos completos (decorrência da racionalidade limitada), as lacunas são inevitáveis. Os agentes, potencialmente oportunistas, sentir-se-ão estimulados a romper ou adimplir os contratos, sendo justificável a existência de um corpo legal, formal, de normas, que se soma às regras informais, para disciplinar o preenchimento das lacunas. Os agentes abster-se-ão de quebrar os contratos se os custos de rompimento forem maiores do que o benefício de fazê-lo.

Define-se, assim, que os custos de transação são os custos incorridos pelas partes no processo de efetivação de uma negociação (BETRAN, 2008, p. 61). Tais custos podem ser de três tipos: (i) custos de busca e obtenção de informações; (ii) custos de negociação e formulação de acordo; e (iii) custos para garantir a execução do contrato. Nos dizeres de WILLIAMSON (1996, p. 267) são "os custos ex ante de rascunhar, negociar e salvaguardar um acordo e, especialmente, os custos ex post decorridos da má adaptação e necessidade de ajustamento, emergente de ocasiões em que a execução contratual é comprometida por lacunas, erros, omissões e perturbações não preditíveis".

Os custos de transação também podem ser compreendidos como os custos de fazer negócios ou os custos de utilização do mercado e não estão relacionados a fatores de produção ou aos bens e serviços em si. Como se costuma afirmar "os custos de transação saem do bolso de uma das partes, mas não entram no bolso da outra” (TIMM; GUARISSE, 2012, p. 167). 
Por serem "pura ineficiência e mero atrito na relação comercial entre dois agentes, indisponível para uso útil” (TIMM; GUARISSE, 2012, p. 168), os custos de transação se inserem nos estudos das falhas de mercado e relacionam-se com a assimetria de informações, que ocorre quando uma das partes de uma transação possui mais informações do que a outra. Nas lições do próprio COASE (2016, p. 114):

A fim de efetuar uma transação no mercado, é necessário descobrir com quem se deseja fazer a transação, informar às pessoas que se quer fazer a transação e em que termos, conduzir as negociações que levam a um acordo, redigir o contrato, realizar as inspeções necessárias para assegurar que os termos do contrato estão sendo cumpridos, e assim por diante. Com frequência, estas operações são extremamente dispendiosas, ou, de qualquer modo, custosas o suficiente para inviabilizar muitas operações que seriam realizadas em um mundo no qual o sistema de determinação de preços funcionasse sem custos. ${ }^{8}$

É necessário frisar e advertir, portanto, que no mundo real esses custos sempre estarão presentes na dinâmica do mercado e não podem ser eliminados inteiramente, mas somente reduzidos. Desse modo, uma forma de reduzir tais custos de transações é por meio da racionalização dos vários procedimentos de contratação (negociação, elaboração e, principalmente, a execução e administração do contrato).

Conforme apontam RIBEIRO e GALESKI JÚNIOR (2019, p. 107), a "questão dos custos de transação importa para o Direito, uma vez que, havendo presença exacerbada, seja de custos de busca, acordo ou execução, há a necessidade de intervenção jurídica, como um arranjo institucional, a fim de tornarem eficientes certas relações econômicas".

Para além da apresentação do conceito de custos de transação, um outro ferramental interessante da análise econômica do direito para o objeto de estudo desta pesquisa é vislumbrado a partir da análise dos contributos da chamada "Teoria dos Custos de Agência". Em apertada síntese, a Teoria dos Custos de Agência busca estudar e analisar os gastos

\footnotetext{
8 Vale indicar também que, na hipotética ausência de custos de transação, problemas de externalidades seriam facilmente resolvidos pelas partes, visto que negociações a fim de atingir soluções eficientes teriam custo zero. É com base nessa suposição que surge o Teorema de Coase, que não foi enunciado pelo próprio Coase, mas, na sua versão original por George Stigler, inspirado pelo artigo "The problem of social Cost". A formulação mais conhecida do teorema pode ser assim enunciada: numa situação de custos de transação zero, a alocação final de um bem, obtida por meio da barganha entre as partes, será sempre eficiente, não importa a configuração legal acerca da propriedade desse bem.
} 
que são decorrentes dos conflitos de interesses ${ }^{9}$ (entre o "principal" e o "agente" ${ }^{10}$ ), inerentes a toda e qualquer organização (notadamente em companhias e demais estruturas empresariais).

De forma bastante semelhante com o que ocorrer como os "custos de transação", os custos de agência podem ser compreendidos como a soma de diversos outros custos, quais sejam: custo de elaboração dos contratos entre o principal e o agente; despesas com o monitoramento das atividades do agente pelo principal; gastos realizados pelo próprio agente para mostrar ao principal que seus atos não serão prejudiciais a ele; e perdas residuais, provenientes da diminuição do principal por eventuais divergências entre decisões do agente e as decisões que iriam maximizar a riqueza do principal (RICHARD; DI MICELI DA SILVEIRA, 2008).

É precisamente nesse sentido - de instrumentalizar as relações econômicas de forma eficiente - que os negócios jurídicos processuais se apresentam, a partir da cláusula geral do art. 190 do CPC/15 - que permite a celebração de negócios atípicos -, como uma forma de flexibilização e adequação do procedimento ao caso concreto, com o intuito de se predefinir (ex ante) as normas processuais (arranjo institucional) que facilitarão a transação comercial, a execução do contrato e/ou inibirão a instauração de eventual conflito e/ou litígio.

Caso seja inevitável a instauração do litígio, que ao menos as partes possam encontrar a melhor forma de dirimi-lo. Sob tal perspectiva, é possível conceber diversos negócios processuais que visam à maior racionalização e previsibilidade na solução das controvérsias; consequentemente, por almejar garantir um processo mais eficiente, que impliquem na redução de custos de transação.

Afinal, conforme bem adverte YARSHELL (2016, p. 92), a abertura que o $\mathrm{CPC} / 15$ confere às partes para que exerçam a sua autonomia privada

\footnotetext{
${ }^{9}$ De acordo com os doutrinadores da economia que estudam essa teoria, os custos de agência surgem em qualquer situação envolvendo esforço cooperativo entre duas ou mais pessoas (JENSEN e MECKLING, 1976).

10 Haverá um "relacionamento de agência" exatamente em circunstânciasque envolvam uma situação - comumente uma relação contratual - onde há a figura do "principal” que tem por objetivo engajar uma ou mais pessoas - então denominado(s) como "agente(s) - para desempenhar alguma atividade em seu favor, mediante a delegação de algum grau de poderes ou de autoridade para que o agente tome decisões e realize a tarefa que lhe foi designada. Nesse sentido, conferir JENSEN e MECKLING, 1976.
} 
em matéria processual não deve ser encarada apenas como uma oportunidade para o exercício da criatividade dos advogados. As alterações feitas pelo legislador devem ser pensadas como forma de trazer resultados relevantes para a racionalização do processo.

Estabelecidas as premissas que norteiam a Teoria da Economia dos Custos de Transação e compreendido o seu conceito, passamos agora à análise da disciplina legal dos negócios jurídicos sob a égide do CPC/15, com o intuito de apresentar seus requisitos, pressupostos e limites.

\section{Negócios jurídicos processuais}

A análise dos negócios jurídicos processuais deve ser precedida de algumas fixações conceituais. Partindo da ideia de que os negócios jurídicos são tipos de fatos jurídicos, torna-se necessário definir primeiramente o que é fato jurídico em razão das diferentes concepções e classificações erigidas em torno do tema (NOGUEIRA, 2016, p. 27).

Conforme ensina JUNQUEIRA DE AZEVEDO (2002, p. 23), "fato jurídico é o nome que se dá a todo fato real sobre o qual incide norma jurídica. Quando acontece, no mundo real, aquilo que estava previsto na norma, esta recai sobre o fato, qualificando-o como jurídico; tem ele, então existência jurídica". Desse modo, a incidência da norma sobre o fato determina, como diz PONTES DE MIRANDA (2000, p. 184), sua entrada no mundo jurídico ${ }^{11}$ (MELLO, 2012, p. 108).

Apesar da divergência doutrinária na classificação dos fatos jurídicos, o presente ensaio se valerá das lições de BERNARDES DE MELLO (2012, p. 146-163), que foi profícuo ao desenvolver a classificação de Pontes De Miranda.

Nesse sentido, rememora-se que os fatos jurídicos se subdividem em: fato jurídico stricto sensu, atos-fatos jurídicos e atos jurídicos lato sensu. Ao presente ensaio, por sua vez, importa destacar esta última categoria, que trata acerca de atos humanos sobre os quais a vontade em praticar o ato não somente é relevante, como constitui o próprio cerne do fato jurídico (MELLO, 2012, p. 178). Nesse sentido, também se subdividem - os atos

\footnotetext{
${ }^{11}$ Trata-se da assim denominada "fenomenologia da juridicização".
} 
jurídicos lato sensu - em duas espécies: os atos jurídicos stricto sensu e os negócios jurídicos. ${ }^{12-13}$

É no âmbito do negócio jurídico que se insere a reflexão proposta neste artigo, uma vez que o que diferencia o ato jurídico em sentido estrito e o negócio jurídico é que por meio deste último o agente tem assegurada a escolha da categoria jurídica e da respectiva estrutura eficacial de seu ato de vontade, sem limitá-lo à pura e simples realização da conduta, mas, também, propiciando a construção voluntária dos respectivos efeitos por meio do exercício da autonomia privada. Vale dizer: é no âmbito do negócio jurídico que a autonomia privada encontra o seu lugar privilegiado.

Importa ressaltar que "a sistemática existente na teoria do direito para o estudo dos atos jurídicos em geral pode ser transposta, em grande medida, para o direito processual, já que os atos do processo são, inegavelmente, espécies de ato jurídico" (CABRAL, 2016, p. 44-45). ${ }^{14}$

12 FACHIN (1988, p. 63-64) apresenta a seguinte distinção: "embora ambos sejam produtos de vontades, é o ato mero pressuposto de efeitos jurídicos, pré-ordenados pela lei, sem função e natureza de autorregulamento. O negócio jurídico estruturalmente consiste em vontade de certo modo preceptiva e funcionalmente serve para dispor, enquanto que o ato não tem como preponderante aquilo que eventualmente dispõe, mas aquilo que é, sendo que a voluntariedade apenas revela efeitos que prescindem de conteúdo volitivo. A essência do negócio jurídico se assenta no autorregulamento de interesse particular, e a do ato se fundamenta na mera tutela da própria esfera, uma vez que o ato jurídico em sentido estrito não é decorrente do exercício da autonomia privada e o interesse objetivado não pode ser regulado pelo particular e sua satisfação se concretiza na maneira determinada por lei. Distingue-se, também, pela finalidade, dado que o escopo buscado pelos figurantes do negócio jurídico é aquele pelos mesmos desejados, enquanto que aquele verificado no ato é o determinado pelo ordenamento jurídico. O conteúdo volitivo é referencial básico à distinção: no negócio jurídico avulta, com efeito, a interpretação, em pertinência à vontade dos integrantes de tal negócio. No ato jurídico em sentido estrito é a lei que fundamentalmente condiciona o conteúdo. Já no negócio jurídico, como consequência da vontade, tem seu conteúdo disposto pela própria vontade que permite autorregulamentar interesses".

13 Ainda, todas as espécies também comportam os fatos contrários a direito, denominados de atos ilícitos. Cf. MELLO, 2012, p. 151-155.

14 Conforme explica DIDIER (2015, p. 372-373), "o fato jurídico adquire o qualificativo de processual quando é tomado como fattispecie (suporte fático) de uma norma jurídica processual e se refira a algum procedimento atual ou futuro. Não há fato jurídico que não se possa relacionar a algum processo (procedimento), mas há fatos jurídicos processuais não integrantes da cadeia procedimental, desde que ocorridos enquanto pendente o procedimento a que estejam relacionados ou se refiram a procedimento futuro. Todo ato humano que uma norma processual tenha como apto a produzir efeitos jurídicos em uma relação jurídica processual pode ser considerado como um ato processual. Esse ato pode ser praticado durante o itinerário do procedimento ou fora do processo. A sede do ato é irrelevante para caracterizá-lo como processual”. 
Ocorre que grande parte da doutrina processualista, pautada pelo publicismo processual, por muito tempo afirmou que a vontade das partes era irrelevante no processo. ${ }^{15}$ Tal posicionamento formou o assim denominado dogma da irrelevância da vontade no processo que também, invariavelmente, acabou por legitimar posições contrárias à admissibilidade de negócios jurídicos processuais (SILVA, 2003, p. 172).

Nesse sentido, CUNHA (2016, p. 49-50) explica que:

As opiniões contrárias à existência do negócio jurídico processual consideram, na realidade, que a vontade não tem qualquer relevância na produção de efeitos pelo ato processual. Desse modo, o sentido juridicamente relevante do ato processual seria objetivo, sem qualquer ligação a elementos estranhos à declaração. Não é sem razão, aliás, que os autores que negam a existência de negócios jurídicos processuais valem-se do fundamento segundo o qual as situações processuais não decorrem de vontade das partes ou de qualquer sujeito do processo, mas de expressas previsões normativas. A vontade da parte seria, então, irrelevante na determinação dos efeitos que os atos processuais produzem. Os efeitos dos atos processuais não seriam, em outras palavras, moldáveis. A única disponibilidade que as partes teriam seria a opção de praticar o ato previsto numa sequência predeterminada pelo legislador. Qualquer que fosse a opção da parte, os efeitos dos atos processuais já estariam tabelados. (...) O dogma da irrelevância da vontade no processo decorre, ainda, do estigma de separar o direito processual [e sua natureza de direito público] do direito material [de natureza de direito privado]. ${ }^{16}$

É bem verdade que, apesar da divergência doutrinária ${ }^{17}$, já havia opiniões favoráveis ao reconhecimento do negócio jurídico processual nos

15 Conforme explica CABRAL (2016, p. 135-136), “O publicismo posicionou o juiz como figura central do processo. Como consequência dessa concepção (...) o juiz pode fazer tudo e as partes não teriam autonomia para quase nada. Como o magistrado deveria perseguir os interesses do Estado, poderia fazê-lo independentemente da vontade individual e, uma vez provocada a jurisdição, a interferência das partes no processo seria mínima. Elas manteriam sua prerrogativa de definir e até renunciar ao direito material subjacente, mas não teriam possibilidade alguma de conformar o procedimento. A função do magistrado seria uma função de soberania, de aplicação do direito objetivo, que não poderia jamais ser resultado, nem mesmo parcial, da atuação privada”.

${ }^{16}$ No mesmo sentido, para conferir mais análises acerca dos efeitos da corrente que afirmava o dogma da irrelevância da vontade, referencia-se: FARIA, 2016., p. 46-47; GODINHO, 2015. p. 111 122.

${ }^{17}$ DIDIER (2015, p. 373) sintetiza a divergência doutrinária acerca do fato jurídico processual em quatro correntes: “a) alguns entendem que é suficiente o produzir efeitos no processo para que o fato seja havido como processual; b) há quem o vincule aos sujeitos da relação processual: apenas o ato por eles praticado poderia ter o qualificativo de processual; c) há os que exigem tenha sido o ato praticado no processo, atribuindo à sede do ato especial relevo; d) há quem entenda que ato processual é o praticado no procedimento e pelos sujeitos processuais”. Destaca-se que esta última 
diplomas processuais anteriores, inclusive sob a vigência do CPC de $1973^{18}$ Para tanto, costuma-se apontar diversos negócios processuais típicos, que já eram previstos no código processual revogado e que foram mantidos pelo CPC/15, tais como: a cláusula de eleição de foro (CPC/73, art. 111 e CPC/15, art. 63), a convenção para suspensão do processo (CPC/73, arts. 265, II e 792 e CPC/15, art. 313, II), a desistência da ação (CPC/73, arts. 158 que no CPC/15, art. 485, §4º: antes da contestação, é um negócio unilateral; após, é bilateral) e tantos outros. ${ }^{19}$

De todo modo, o advento da cláusula geral prevista no art. 190 do CPC/15 acaba com a controvérsia, pois outorga positivação ${ }^{20}$ ao fenômeno de valorização da autonomia privada no âmbito processual e de atenuação da visão exclusivamente publicista do processo (CAMBI; DOTTI; KOZIKOSKI, 2017, p. 198; ABREU, 2016, p. 281-302).

Muito além do que simplesmente aumentar o rol de negócios processuais típicos (v.g., ao prever a possibilidade de fixação de calendário processual nos termos do art. 191 ou de escolha consensual do perito conforme dispostono art. 471), o CPC/15 passa a permitir expressamente que as partes celebrem convenções (negócios jurídicos bilaterais ou plurilaterais) atípicas, antes ou durante o processo, acerca do procedimento, para ajustá-lo às especificidades da causa (isto é, no rito

\footnotetext{
é a posição adotada por CALMON DE PASSOS (2002, p. 43), in verbis: "Donde conceituar o ato processual com o aquele que é praticado no processo, pelos sujeitos da relação processual ou do processo, com eficácia no processo e que somente no processo pode ser praticado”. Assim, também, é a posição de Daniel Mitidiero (2005, p. 14).

18 Ainda sob égide do CPC/73, muitos autores já afirmavam que o art. 158 - que possui correspondência com o art. 200 do CPC/15 - já era suficiente para se afirmar a possibilidade de reconhecimento de negócios jurídicos processuais, visto que dispunha que "os atos das partes, consistentes em declarações unilaterais ou bilaterais de vontade, produzem imediatamente a constituição, a modificação ou a extinção de direitos processuais”. A despeito de terem existido outros ensaios anteriores sobre o tema - inclusive com uma tímida manifestação por Pontes De Miranda (1974) -, a doutrina mais recente tem afirmado que, no Brasil, cronologicamente, o estudo mais aprofundado sobre o tema foi o de Barbosa Moreira, ainda na década de 80. Após longos anos, em 2007, um ensaio provocativo de Leonardo Greco fez com que o tema voltasse a receber a devida atenção pela doutrina nacional.

19 CUNHA (2016, p. 54-55) apresenta trinta e três exemplos de negócios processuais típicos extraídos do CPC/73.

${ }^{20}$ Conforme assevera Didier (2015, p. 379-380), com as disposições expressas do CPC/15, firmar posicionamento contrário à existência de negócios jurídicos processuais "será simplesmente contra legem". De forma definitiva, o Autor também conclui afirmando que "A discussão sobre a existência dessa categoria processual, ao menos no Brasil, parece, agora, obsoleta e inócua”.
} 
imposto pela lei para a prática de atos processuais) ou de seus ônus, poderes, faculdades e deveres processuais (situações processuais). ${ }^{21}$

É inegável, portanto, que o $\mathrm{CPC} / 15$ reconhece às partes não somente a possibilidade de participar ativamente do processo e de influenciar na solução do caso concreto, mas também confere-lhes a liberdade para construir o procedimento que melhor atenda aos seus interesses, ampliando, com isso, o seu feitio democrático (RAATZ, 2016, p. 188).

A consagração do princípio da cooperação (art. 6º, CPC/15) e a adoção do modelo cooperativo de processo se relacionam com o fenômeno de reconhecimento da vontade das partes (FARIA, 2016, p. 106; MÜLLER 2016, p. 71-85; CUNHA, 2016, p. 57-62). Afinal, o modelo cooperativo de processo caracteriza-se exatamente por articular os papéis processuais das partes e do juiz, com o propósito de harmonizar a eterna tensão entre a liberdade individual e o exercício do poder pelo Estado. ${ }^{22}$

É somente a partir desse modelo cooperativo que se justifica, inclusive, afirmar a existência de um princípio específico que também norteia o CPC/15: o princípio do respeito ao autorregramento da vontade no processo. Princípio que visa, enfim, à obtenção de um ambiente processual em que o direito fundamental da liberdade e, como decorrência desta, o de autorregular-se possa ser exercido pelas partes sem restrições irrazoáveis ou injustificadas (DIDIER, 2016, p. 31-37).

Vale dizer: define um espaço de não coerção (liberdade negativa) para o exercício de escolhas vinculantes (liberdade positiva), no atendimento de seus interesses particulares (RUZYK, 2011).

É claro que a autonomia privada também sofre limitações no âmbito do processo quando da análise do princípio no âmbito do direito material. Trata-se de decorrência lógica da própria decomposição conceitual da autonomia privada que se define em um espaço de liberdade negativa e que, ao seu turno, pressupõe a existência de um lugar externo em que se

\footnotetext{
${ }^{21}$ Cabe apontar que o Enunciado n. 258 do Fórum Permanente de Processualistas Civis (FPPC) é no sentido de que "As partes podem convencionar sobre seus ônus, poderes, faculdades e deveres processuais, ainda que essa convenção não importe ajustes às especificidades da causa”.

22 Como ilustra metaforicamente DIDIER (2015, p. 133): “o processo colaborativo nem é processo que ignora a vontade das partes, nem é processo em que o juiz é mero espectador de pedra”.
} 
opera a coerção. Os limites externos são, sob o ponto de vista do direito, os instrumentos de coerção a delimitar o campo dessa liberdade negativa.

Contudo, é necessário frisar que o simples fato de o processo ter caráter público não significa, por si só, a negação de espaço à liberdade e à autonomia privada das partes (RAATZ, 2016, p. 186). Muito pelo contrário. Conforme GODINHO (2015, p. 27-41), “a realização de negócios jurídicos processuais constitui, na realidade, uma manifestação de um processo jurisdicional democrático ${ }^{23}$, sem que se vislumbre, com isso, a sacralização do privatismo ou do publicismo; almeja-se, na realidade, a efetiva realização de direitos". 24

Compreendidas as bases que conformaram o CPC/15 e que inegavelmente sepultam quaisquer dúvidas acerca da possibilidade de celebração de negócios jurídicos processuais, resta-nos agora verificar quais são seus requisitos e pressupostos legais.

Como todo e qualquer negócio jurídico, os negócios processuais passam pelos planos da existência, validade e eficácia. ${ }^{25}$ Desse modo, os negócios jurídicos processuais devem preencher os elementos de existência (sujeitos, objeto, manifestação de vontade e forma), bem como os requisitos de validade que qualificam os elementos de existência, quais sejam: capacidade dos agentes, licitude, possibilidade e determinabilidade do objeto, higidez da manifestação volitiva ${ }^{26}$ e a forma prescrita ou não defesa

\footnotetext{
${ }^{23}$ CUNHA (2016, p. 61) afirma, ao tratar do modelo cooperativo, que: "há, no novo Código, uma valorização do consenso, e uma preocupação em criar no âmbito do judiciário um espaço não apenas de julgamento, mas de resolução de conflitos. Isso propicia um redimensionamento e democratização do próprio papel do Poder Judiciário e do modelo de prestação jurisdicional pretendido".

${ }^{24} \mathrm{O}$ autor ainda continua dizendo que "o estudo sobre os fatos processuais, mais precisamente sobre os negócios jurídicos processuais, mostra-se igualmente fundamental, na medida em que se deve mensurar precisamente os limites e as possibilidades da atuação das partes, não mais, repita-se, com uma visão privatística, e muito menos com um viés estatitazente, que rechaça a participação dos destinatários do resultado do processo, como se fossem figuras incapazes e, até, inconvenientes" (GODINHO, 2015, p. 27-41).

${ }^{25}$ Com apoio nas lições de PONTES DE MIRANDA, JUNQUEIRA (2002, p. 23-24) propõe o tratamento do negócio jurídico tomando por base um critério de exclusão: deve o intérprete verificar sucessiva e progressivamente se o negócio jurídico é existente; depois, sendo existente se é válido; depois, se for válido, se é eficaz. Cf. CABRAL, 2016, p. 255.

${ }^{26}$ Neste sentido, aponta-se o teor do Enunciado n. 132 do Fórum Permanente de Processualistas Civis (FPPC): "Além dos defeitos processuais, os vícios de vontade e os vícios sociais podem dar ensejo à invalidação dos negócios jurídicos atípicos”.
} 
em lei (art. 104 do Código Civil). ${ }^{27}$ Além destes, há os requisitos específicos dispostos no artigo 190 do CPC/15.

No que diz respeito à plena capacidade do agente, pressuposto subjetivo para a realização dos negócios processuais, é necessário que: i) o sujeito detenha a capacidade de ser parte, sendo titular de direitos e obrigações; e ii) possua capacidade de estar em juízo, podendo ser assistido ou representado - em conformidade com os arts. $1^{\circ}, 3^{\circ}, 4^{\circ}, 166$, inciso I e 171, inciso I, do Código Civil e arts. 70 a 76 do CPC/15 (CAMBI; DOTTI; KOZIKOSKI, 2017, p. 201).

O que importa para os negócios processuais é a capacidade de estar em juízo (TALAMINI, 2015, p. 4). Nesse sentido, vislumbra-se a possibilidade de um condomínio (apesar de não possuir personalidade jurídica) poder celebrar negócio jurídico, desde que representado por seu administrador ou síndico (CPC/15, art. 75, XI), ou a massa falida, por seu administrador judicial (CPC/15, art. 75, V) e também o incapaz (absoluta ou relativamente), desde que adequadamente representado ou assistido por seus pais, tutor ou curador - vide CPC/15, art. 71 (CAMBI; DOTTI; KOZIKOSKI, 2017, p. 201).

A doutrina diverge sobre a relevância da vulnerabilidade da parte frente ao plano da validade e ao plano da eficácia. Nessa linha, colhe-se do pensamento de DIDIER (2015, p. 384-86) no sentido que o requisito de validade exigido para prática dos negócios processuais é a "capacidade processual negocial, que pressupõe a capacidade processual, mas não se limita a ela, pois a vulnerabilidade é caso de incapacidade processual negocial".

Nesse sentido, o parágrafo único do art. 190 traria uma hipótese específica de incapacidade processual negocial: a incapacidade pela situação de “manifesta vulnerabilidade”. Em sentido diverso, porém, Talamini (2015, p. 6-7) afirma que "o negócio processual encontra um limite de eficácia na vedação ao abuso" Trata-se de um parâmetro restrito para a negativa de eficácia ao negócio processual - expresso na exigência de que a situação de vulnerabilidade seja manifesta. É também nesse

\footnotetext{
${ }^{27}$ Este é o teor do Enunciado n. 403 do FPPC: “A validade do negócio jurídico processual, requer agente capaz, objeto lícito, possível, determinado ou determinável e forma prescrita ou não defesa em lei".
} 
sentido que se observa que é possível a inserção de negócio processual no âmbito de contrato de adesão, desde que não se configure abusividade (TALAMINI, 2015). ${ }^{28}$

Embora, não se descarte a possibilidade de em dados casos concretos se verificar a vulnerabilidade mesmo no âmbito de contratos empresariais, trata-se de hipótese a ser analisada caso a caso, partindo-se, porém, prima facie, da presunção de paridade dos agentes de mercado.

O dispositivo também não exige, obrigatoriamente, capacidade postulatória ou sequer a presença de advogado (acompanhamento técnicojurídico) para a celebração de negócio jurídico processual. Contudo, é sensato o Enunciado no 18 do Fórum Permanente de Processualistas Civis (FPPC) que dispõe que "há indício de vulnerabilidade quando a parte celebra acordo de procedimento sem assistência técnico-jurídica”. ${ }^{29}$

Relacionado com o objeto, o pressuposto objetivo genérico para celebração de convenções processuais é a aptidão de o direito submeter-se à autocomposição. Em linhas gerais, admitir autocomposição consiste na possibilidade de resolução do conflito extrajudicialmente - isto é, sem a atuação do Estado. Observe-se que não se trata de disponibilidade do direito material (como no caso da arbitragem - art. $1^{\circ}$ da Lei 9.307/96). Ainda que os direitos disponíveis constituam, por excelência, o campo para a autocomposição, há inúmeras situações de direitos indisponíveis em que é perfeitamente possível a solução consensual (CAMBI; DOTTI; KOZIKOSKI, 2017, p. 197). ${ }^{30}$

\footnotetext{
28 Talamini (2015) exemplifica uma hipótese interessante: "uma instituição financeira pode inserir em um contrato de adesão que celebra com seus clientes a previsão de que as citações dela deverão fazer-se por via eletrônica (com fulcro no art. $246, \S 1^{\circ}$ ). Tal avença confere segurança à instituição financeira sem implicar nenhum sacrifício para o cliente, pois a citação eletrônica é simples, rápida e sem custos".

${ }^{29}$ Como analisa YARSHELL (2016, p. 88), “a validade do negócio processual não está condicionada à presença de advogado - embora evidentemente seja desejável por se tratar de matéria técnica, que presumivelmente escapa do conhecimento do leigo. $\mathrm{O}$ fato de o negócio jurídico ter por objeto atos que integram o procedimento e posições jurídicas que compõem a relação processual não é suficiente para tornar obrigatória a presença do advogado no ato da celebração do negócio. Para que isso ocorresse seria indispensável previsão legal expressa, tal como ocorre no caso de atos constitutivos de pessoas jurídicas (...), que além de expresso, comina taxativamente a sanção de invalidade”. Cf. FARIA, 2016, p. 91.

${ }^{30}$ Aponta-se o teor do Enunciado n. 13 do FPPC: "A indisponibilidade do direito material não impede, por si só, a celebração de negócio jurídico processual”. Jamais se discutiu, por exemplo, a
} 
O objeto lícito pressupõe que o conteúdo do negócio jurídico não seja vedado pelo ordenamento jurídico, nem contrarie norma cogente. Nesse sentido, como acertadamente observa DIDIER (2015, p. 387), "o objeto do negócio é o ponto mais sensível e [ainda] indefinido na dogmática da negociação processual atípica". Não obstante, a primeira diretriz apontada pelo mesmo autor é de que, ressalvada alguma regra que imponha uma interpretação restritiva ${ }^{31}$, na dúvida deve se admitir o negócio processual (in dubio pro libertate).

Quanto à forma, Didier (2015, p. 389) afirma que "a forma do negócio processual atípico é livre. [Sendo possível] negócio jurídico oral ou escrito, expresso ou tácito, apresentado por documento extrajudicialmente ou em mesa de audiência”. Sob esse ângulo, para ser válido, o negócio processual não está sujeito à forma especial, tendo em vista principalmente o claro teor do art. 166, IV do Código Civil (FARIA, 2016, p. 100).

Segundo YARSHELL (2016, p. 85), não há exigência de que o negócio jurídico processual seja celebrado por instrumento público e "ainda que celebrado por instrumento particular, este deverá ser juntado aos autos e, nessa medida, ganhará a forma pública”. Caso seja celebrado em audiência, na presença do juiz, este deverá ser reduzido a termo (FARIA, 2016, p. 99). Entretanto, se celebrado extrajudicialmente, recomenda-se que seja formulado na forma escrita, facilitando-se, assim, a prova da sua realização e para que se submeta, via de consequência, ao controle de validade e eficácia do juiz nos termos do parágrafo único do art. 190 do CPC/15.

Do ponto de vista da sua eficácia, os negócios processuais geram, via de regra, efeitos imediatos, independente da homologação judicial (CPC/15, art. 200). Em algumas hipóteses específicas, entretanto, sua eficácia está condicionada à homologação pelo juiz. É o caso de desistência da ação, nos termos do parágrafo único do mesmo artigo 200; da fixação de calendário nos termos do art. 191, ou até mesmo de delimitação

possibilidade de alteração das regras de competência relativa (CPC/15, art. 63), independentemente da (in)disponibilidade do direito material.

${ }^{31}$ Nesse sentido, aponta-se o teor do Enunciado n. 20 do FPPC: "Não são admissíveis os seguintes negócios bilaterais, dentre outros: acordo para modificação da competência absoluta, acordo para supressão da primeira instância, acordo para afastar motivos de impedimento do juiz, acordo para criação de novas espécies recursais, acordo para ampliação das hipóteses de cabimento de recursos". 
consensual das questões de fato e de direito, nos termos do $§ 2^{\circ}$ do art. 357 . Tais exemplos, contudo, não afastam a regra geral de eficácia imediata. Ao contrário, demonstram que a suspensão da eficácia tem que estar expressamente prevista no ordenamento (CAMBI; DOTTI; KOZIKOSKI, 2017, p. 202-203). ${ }^{32}$

Quanto ao controle da validade, cumpre ressaltar que os postulados do princípio da conservação dos negócios, com a construção teórica da preservação teleológica dos atos animados pela vontade, por certo haverão de impactar na percepção do Juiz ao apreciar a validade dos negócios processuais. Se a doutrina e a jurisprudência se inclinam para a preservação dos negócios de maneira geral (GUERRA, 2016), não há sentido na construção de modo de agir distinto para os negócios jurídicos processuais. ${ }^{33}$

A decretação de invalidade dos negócios processuais deve obedecer ao sistema de invalidades processuais (CPC/15, art. 276 a 283), o que significa dizer que deve esta ser decretada pelo juiz e que não haverá nulidade sem prejuízo (ne pas de nullité sans grief). ${ }^{34}$ Também como qualquer negócio jurídico, há a possibilidade de invalidação parcial do negócio jurídico processual (DIDIER, 2015, p. 384). ${ }^{35}$

Compreendidos os pressupostos e requisitos dos negócios jurídicos processuais, passamos agora a analisar a correlação entre os negócios processuais e a eficiência processual sob o contexto específico dos contratos empresariais.

\section{Negócios processuais e eficiência processual}

Uma das vantagens mais evidentes dos negócios processuais é precisamente a possibilidade de se buscar uma adequação do

\footnotetext{
${ }^{32}$ Nesse sentido é o teor do Enunciado n. 133 do FPPC: "salvo nos casos expressamente previstos em lei, os negócios processuais do art. 190 não dependem de homologação judicial”.

33 Também é importante ressaltar o Enunciado n. 259 do FPPC, no sentido de que: "a decisão referida no parágrafo único do art. 190 depende de contraditório prévio”.

${ }^{34}$ Diz o Enunciado n. 16 do FPPC: "o controle dos requisitos objetivos e subjetivos de validade da convenção de procedimento deve ser conjugado com a regra segundo a qual não há invalidade do ato sem prejuízo".

${ }^{35}$ Este é também o exato teor do Enunciado n. 134 do FPPC.
} 
procedimento ao caso concreto e, consequentemente, a obtenção de uma maior eficiência processual (CABRAL, 2016, p. 194).

O termo eficiência tem diversas acepções. Neste ensaio, eficiência diz respeito à maximização de ganhos e minimização de custos. ${ }^{36}$ Sob tal ótica, um processo será considerado eficiente se for possível a obtenção do máximo de benefícios com o emprego do mínimo de custos.

Como visto, o CPC/15, ao tempo em que abre espaço à participação das partes na construção do procedimento, democratizando-o, também se preocupa em evitar que esses acordos, na prática, funcionem como instrumento de abuso de direito. Por isso, somente será permitida a celebração de negócios processuais quando: (i) se tratar de direitos passíveis de autocomposição; (ii) quando as partes sejam capazes e (iii) estejam em situação de equilíbrio, não se admitindo a pactuação de negócios processuais inseridos abusivamente em contratos de adesão ou em contratos em que figurem partes em manifesta situação de vulnerabilidade (NOGUEIRA, 2016, p. 103).

A seara do direito empresarial, tendo por pressuposto a simetria do poder de contratação, é fértil para o desenvolvimento desse mecanismo de flexibilização dos atos processuais, visando privilegiar a autonomia privada das partes e uma maior eficiência para a solução de litígios concretos.É certo e natural que os contratos empresariais aumentam seu potencial de produzir riquezas em um ambiente que privilegie a segurança e a previsibilidade jurídicas (FORGIONI, 2015, p. 119). Nesse sentido, os negócios processuais emprestam maior segurança e previsibilidade ao tráfego jurídico na medida em que incrementam a certeza da aplicação de regras processuais - afinal, se as regras tivessem que ser livremente aplicadas e interpretadas, o resultado seria incerto (CABRAL, 2016, p. 203).

Nesse sentido, é imperioso mencionar as recentes e relevantes modificações operadas pela Lei no 13.874/2019, que instituiu a "Declaração de Direitos de Liberdade Econômica", e passou a ser denominada apenas como "Lei de Liberdade Econômica" (LEE), que traz diversas alterações na

\footnotetext{
${ }^{36}$ Há outras duas acepções do termo eficiência que neste texto deixaremos de lado: a eficiência paretiana e a eficiência de Kaldor-Hicks. Cf. SALAMA, 2008, p. 55.
} 
disciplina legal da interpretação dos negócios jurídicos, sobretudo com o objetivo de ampliar a liberdade e a segurança nas relações negociais (KONDER; OLIVEIRA, 2020, p. 13-35).

Com efeito, e com total pertinência ao objeto desta pesquisa, as novas regras interpretativas, positivadas no artigo 113 e pela inclusão do art. 421 A no Código Civil, reforçam precisamente o pressuposto, que já era apontado pela doutrina, da existência de uma simetria do poder de contratação nas relações civis e, ainda mais notadamente, nas de cunho empresarial.

Deste modo, conforme destacado pela nova redação dessas regras interpretativas supramencionadas, o Código Civil passou a dispor, de forma expressa, que os contratos civis e empresariais se presumem paritários e simétricos. Além disso, que a alocação de riscos definida pelas partes deve ser respeitada e observada, e a revisão contratual somente ocorrerá de maneira excepcional e limitada (MARQUES NETO; RODRIGUES JR.; LEONARDO, 2019, p. 293-363).

Assim, os negócios processuais se apresentam como uma forma de racionalização do processo na medida em que permitem a predefinição (ex ante) das normas (arranjo institucional) que facilitarão a transação comercial, a execução do contrato e/ou inibirão a instauração de eventual litígio. Se for inevitável a instauração do litígio, que ao menos as partes possam encontrar a melhor forma de dirimi-lo. Como consequência, e como benefício econômico, tem-se a redução dos custos.

Nessa toada, ao tratar do ganho de eficiência processual, CABRAL (2016, p. 200-205) sustenta precisamente que:

[O] acordo [negócio jurídico processual] passou a ser também um mecanismo de gestão, adaptando a tramitação do procedimento às especificidades dos interesses das partes. Ao invés de impor às partes uma justiça prêt-à-porter, admite-se uma justiça feita 'sob medida' (tailor-made). (...) A prática contratual tem se adaptado às possibilidades e vantagens dos acordos processuais. Nos acordos prévios, trata-se de uma antecipação contratual da litigância: quanto mais alternativas procedimentais se colocam para as partes em um potencial litígio, a fim de adaptálos às suas necessidades, mais utilidade os acordos processuais assumem no plano da eficiência, considerada em uma perspectiva ex ante”. (...) Os acordos processuais 
podem reduzir também o ônus financeiro do processo, sobretudo pela redução dos chamados custos de transação. ${ }^{37}$

Exatamente por exigir uma atitude de cooperação, inseridos dentro de um modelo colaborativo de processo que lhes dá maior autonomia, os agentes de mercado podem aumentar os seus ganhos a partir do incentivo para realização de novas transações e prolongamento das relações comerciais já estabelecidas exitosamente.

Afinal, como destaca Müller (2017, p. 366), "a adversidade quanto aos interesses de mérito não deve se confundir quanto à cooperação em termos de processo (...). Cooperar processualmente [resguardadas algumas situações óbvias que poderão implicar em prejuízo da própria parte] é racionalmente mais eficiente do que competir". É nesse sentido que KLEIN (2013. p. 92-93) também afirma:

A adoção de uma atitude de cooperação nos contratos empresariais é eficiente para os contratantes, na medida em que reduz custos de transação. Afinal, um ambiente institucional capaz de fomentar a confiança é um ambiente benéfico às transações econômicas. (...) Um ambiente cooperativo que favoreça a confiança permite que as transações sejam mais eficientes na geração de ganhos. A observância do princípio do equilíbrio contratual não como uma obrigação de distribuição equânime, mas sim como uma obrigação de distribuição desses ganhos com um nível razoável de reciprocidade é um incentivo importante para que novas transações e novos investimentos sejam feitos. ${ }^{38}$

São diversos os exemplos que podem ilustrar o raciocínio apresentado até aqui. Pensemos, ilustrativamente, em um contrato atípico de

\footnotetext{
${ }^{37} \mathrm{O}$ autor ainda prossegue: “as trocas econômicas entre os contratantes abrangem não só os custos das negociações preliminares, na identificação de interessados, os de produção e entrega da prestação de cada qual, mas também a fiscalização ou monitoramento do cumprimento da contraparte (confirmação de pagamento, cobrança de parcelas em atraso, testes de qualidade do produto). Os acordos processuais, por conseguinte, ao imprimirem previsibilidade ao processo, permitem uma melhor avaliação de custo-benefício da litigância, reduzem o estado de incerteza que este gera, diminuem os custos de transação, e tornam as relações econômicas mais interessantes. Além disso, podem gerar economia, minimizando os custos de implementação e criando incentivos para o adimplemento. De maneira geral, a economia processual, tanto no viés da simplificação de atos quanto na redução de tempo e custos, pede soluções desburocratizadas. Tanto melhor será que estas soluções sejam amigáveis, negociais, convencionadas” (CABRAL, 2016, p. 200-205).

38 No sentido, SCHUNCK (2016, p. 84) afirma: “a cooperação entre contratantes acaba sendo fator crucial para a redução de custos de transação, evitando desgastes desnecessários das partes. O papel que a cooperação desempenha em contratos é justamente o de redução de custos e de possibilitar o desempenho ótimo das contratações, trazendo assim benefícios que podem ser, inclusive, econômicos".
} 
licenciamento e cessão para exploração de patente e uso de marca, onde uma empresa "A", detentora da titularidade da patente " $X$ " e da marca "Y", pactua com a empresa "B" para que esta última fique responsável por produzir industrialmente um determinado produto "Z" para comercializálo em certos estados do país. Em contrapartida, com base no percentual de vendas do produto "Z", a empresa "B" deverá pagar royalties à empresa "A". Há, sem dúvida, uma enorme dificuldade para que a empresa "A" tenha controle acerca da qualidade e quantidade dos produtos fabricados e comercializados pela empresa "B". Por sua vez, a empresa "B" pode ter um enorme custo para conseguir comprovar, regularmente, que está seguindo à risca todas as obrigações assumidas frente à empresa "A".

A assimetria informacional e a possibilidade de comportamento oportunista implicam em custos de transação para ambas as partes.

Por esta razão, as partes podem pactuar livremente: (a) a eleição convencional de um foro que seja equidistante para as duas partes (CPC/15, art. 63); (b) convenção para estabelecer métodos atípicos de comunicação entre as partes; (c) acordo para disponibilização prévia de documentos (pacto de disclosure); (d) pacto de mediação ou conciliação extrajudicial prévia obrigatória; (e) acordo para rateio de despesas processuais e honorários; (f) a escolha consensual e prévia do perito (CPC/15, art. 471); (g) dispensa consensual de assistente técnico; (h) pacto para determinar a penhorabilidade ou impenhorabilidade de determinados bens; (i) acordo para incluir ou retirar o efeito suspensivo dos recursos; (j) convenção para distribuição do ônus da prova (v. g., para determinar que a empresa "B" deverá guardar um "lote de controle" de cada produto sobre o qual recairá perícia para verificação de sua qualidade); (k) acordo para limitação do número de testemunhas ou de dispensa de produção de prova oral; etc. ${ }^{39}$

A criatividade é livre para se pensar em tantos outros exemplos a partir de negócios jurídicos típicos e atípicos. De todo modo, ainda é um tanto quanto cedo para se ter certeza acerca dos limites que conformarão o tema; a doutrina acerca do assunto é relativamente incipiente e não há decisões em quantidade suficiente de modo a permitir apontar a formação de um entendimento jurisprudencial. Entretanto, tais fatos não impedem

\footnotetext{
${ }^{39}$ Boa parte dos exemplos indicados aqui foram formulados a partir do Enunciado n. 19 do FPPC.
} 
que se defendam - não apenas do ponto de vista teórico, mas com perspectiva prática - como positivas as alterações trazidas pelo CPC/15. Nesse sentido, cabe citar a visão otimista, mas também com advertências, apresentada por TALAMINI (2015, p. 19-20):

A experiência dirá qual dimensão a regra autorizadora de negócios processuais atípicos vai assumir no sistema processual civil instaurado pelo Código de 2015. Potencialmente, essa norma tem o condão de alterar de modo substancial a função e a eficácia dos mais diversos institutos e mecanismos - sejam aqueles que ora surgem como novidade, sejam os que, em si mesmos considerados, mantêm-se formalmente iguais ao que antes eram. (...)Mas também é possível que os negócios processuais sejam um malogro em termos práticos. Não seria a primeira nem a última vez que isso estaria acontecendo: um instituto a despertar a atenção dos estudiosos, por sua sofisticação e riqueza de possibilidades, e a afugentar os práticos exatamente pelos mesmos motivos... Essa segunda hipótese não é a desejável. (...)Cabe a todos os estudiosos e profissionais do direito procurar caminhos e soluções para que a primeira das duas hipóteses ora aventadas se concretize. Para isso, o debate sobre o tema é fundamental.

Assim, em atendimento ao chamado público feito a todos os estudiosos e profissionais do direito para o debate do tema, o presente artigo buscou demonstrar como o negócio jurídico processual tem potencial de ser um instituto muito valioso também em termos práticos, notadamente quando inseridos no contexto específico dos contratos empresariais.

\section{Conclusão}

Neste ensaio buscamos apresentar argumentos que militam em favor da possibilidade de se pensar nos negócios jurídicos processuais, a partir do advento do CPC/15, como instrumentos de racionalização do processo e, consequentemente, de redução de custos de transação inseridos no contexto específico dos contratos empresariais. Este raciocínio, que já era defendido em doutrina, também foi inegavelmente fortalecido pelas recentes modificações ocorridas sobre a disciplina legal da interpretação dos negócios jurídicos civis e empresariais, trazidas pela Lei de Liberdade Econômica, sobretudo com o objetivo de ampliar a liberdade e a segurança nas relações negociais.

Para fundamentar tal conclusão, realizamos um breve panorama acerca da corrente da Análise Econômica do Direito, com foco no intuito 
específico de se compreender as premissas que norteiam a Teoria dos Custos de Transação. Também analisamos, com perspectiva crítica, a disciplina legal dos negócios jurídicos sob a égide do CPC/15 com o objetivo principal de apresentar seus requisitos, pressupostos e limites. Por fim, apresentamos a correlação entre os negócios processuais e a eficiência processual, a partir da premissa de que o direito empresarial, tendo por pressuposto a simetria do poder de contratação, é fértil para o desenvolvimento desse mecanismo de racionalização e de flexibilização dos atos processuais e que visa privilegiar a autonomia privada na solução de litígios concretos.

Ademais, após percorrido, de forma concisa, o caminho travado pelos negócios processuais e feitas as devidas aproximações e considerações dos seus benefícios à seara econômica, sobretudo no âmbito empresarial, foi possível concluir também acerca de sua importância enquanto instituto emancipador dos jurisdicionados. Como bem se expôs, sua aplicação viabiliza um âmbito fértil ao desenvolvimento do direito fundamental à liberdade, exaltando o indivíduo enquanto sujeito capaz de tomar decisões em oposição a uma figura do Estado enquanto tutor dos interesses de toda coletividade de modo irrestrito e senhorial.

Dessa forma, estabelecido um panorama que se encarregou de abordar, ao menos brevemente, aspectos econômicos, processuais e negociais, pôde-se concluir não apenas pela possibilidade dos negócios jurídicos processuais como instrumentos representativos da liberdade contratual e de autonomia das partes, como também, e a despeito de todo o embate privatista-publicista, de eficácia processual. Nesse sentido, entende-se que a disseminação do uso de tais mecanismos processuais pode acarretar não somente na otimização do processo sob uma perspectiva singular, como também impactar no sentimento de segurança das partes em contratar, base inequívoca para o desenvolvimento econômico de uma sociedade.

\section{Referências bibliográficas}

AGUSTINHO, Eduardo Oliveira; CRUZ, Rafael Augusto Firakowski. A opção pela arbitragem como medida de salvaguarda para a redução dos custos de transação. In: RIBEIRO, Marcia Carla Pereira e KLEIN, Vinicius (Org.). 
Reflexões acerca do direito empresarial e a análise econômica do direito. Curitiba: GEDAI-UFPR, 2014.

ARAÚJO, Fernando. Teoria económica do contrato. Coimbra: Almedina, 2007.

AZEVEDO, Antônio Junqueira de. Negócio Jurídico - Existência, Validade e Eficácia. - São Paulo: Saraiva, 2002.

CABRAL, Antônio do Passo. Convenções processuais. Salvador: JusPodivm, 2016.

CAMBI, Eduardo; PINHEIRO, Paulo; DOTTI, Rogéria; MARTINS, Sandro; KOZIKOSKI, Sandro. Curso de Processo Civil Completo. - São Paulo: RT, 2017.

COASE, Ronald H. A firma, o mercado e o direito. - Rio de Janeiro: Forense Universitária, 2016.

DIDIER JR., Fredie. Curso de direito processual civil: introdução ao direito processual civil, parte geral e processo de conhecimento. 17. ed. - Salvador: JusPodivm, 2015.

FACHIN, Luiz Edson. Novo Conceito de ato e negócio jurídicos: consequências práticas. - Curitiba: EDUCA, SCIENTIA et LABOR, 1988.

FARIA, Guilherme Henrique Lage. Negócios processuais no modelo constitucional de processo. Salvador: JusPodivm, 2016.

FORGIONI, Paula. Teoria Geral dos Contratos Empresariais. São Paulo: RT, 2009.

GODINHO, Robson Renault. Negócios processuais sobre o ônus da prova no novo código de processo civil. São Paulo: RT, 2015.

GUERRA, Alexandre. Princípio da conservação dos negócios jurídicos. - São Paulo: Almedina, 2016.

JENSEN, M.; MECKLING, W. Theory of the firm: managerial behavior, agency costs and ownership structure. Journal of Financial Economics, v. 3, n. 4, p. 305360, 1976.

KLEIN, Vinicius. Os Contratos Empresariais de Longo Prazo - uma análise a partir da argumentação judicial. Tese (doutorado). Universidade do Estado do Rio de Janeiro, Faculdade de Direito, 2013.

KONDER, Carlos Nelson. OLIVEIRA, Williana Nayara Carvalho de. A interpretação dos negócios jurídicos a partir da Lei de Liberdade Econômica. R. Fórum de Dir. Civ. - RFDC | Belo Horizonte, ano 9, n. 25, p. 13-35, set./dez. 2020

MARQUES NETO, Floriano Peixoto. RODRIGUES JR., Otavio Luiz. LEONARDO, Rodrigo Xavier (Coord.). Comentários à Lei de Liberdade Econômica: Lei 13.874/2019. - São Paulo: Thomson Reuters, 2019.

MELLO, Marcos Bernardo de. Teoria do fato jurídico: plano de existência. 18 ed. - São Paulo: Saraiva, 2012.

MIRANDA, Pontes de. Tratado de direito privado. Campinas: Bookseller, 2000.

MITIDIERO, Daniel. Colaboração no processo civil: pressupostos sociais, lógicos e éticos. 3. ed.- São Paulo: Editora Revista dos Tribunais, 2015. 
MÜLLER, Júlio Guilherme. Negócios Processuais e desjudicialização da produção da prova - Análise Econômica e Jurídica. - São Paulo: Editora RT, 2017.

PASSOS, José Joaquim Calmon de. Esboço de uma teoria das nulidades aplicada às nulidades processuais. - Rio de Janeiro: Forense, 2002.

RAATZ, Igor. Autonomia privada e processo civil: negócios jurídicos processuais, flexibilização procedimental e o direito à participação na construção do caso concreto. - Salvador: JusPodivm, 2016.

RIBEIRO, Marcia Carla; GALESKI JÚNIOR, Irineu. Teoria Geral dos contratos: contratos empresariais e análise econômica. - Rio de Janeiro: Elsevier, 2009.

RUZYK, Carlos Eduardo Pianovski. Institutos Fundamentais do Direito Civil e liberdade(s). Rio de Janeiro: GZ, 2011.

SAITO, Richard; DI MICELI DA SILVEIRA, Alexandre. Governança corporativa: custos de agência e estrutura de propriedade. RAE - Revista de Administração de Empresas, v. 48, n. 2, abril-jun., 2008, p. 79-86. - Fundação Getúlio Vargas: São Paulo, Brasil. ISSN: 0034-7590. Disponível em: https://www.redalyc.org/articulo.oa?id=155116085007. Acesso em março de 2021.

SALAMA, Bruno Meyerhof. O que é "Direito e Economia"? In: TIMM, Luciano Benetti; et al. Direito \& economia. - Porto Alegre: Livraria do Advogado, 2008.

SCHUNCK, Giuliana Bonanno. Contratos de longa duração e dever de cooperação. - São Paulo: Almedina, 2016.

SILVA, Paula Costa e. Acto e Processo - o dogma da irrelevância da vontade na interpretação e nos vícios do acto postulativo. - Coimbra: Coimbra, 2003

TALAMINI, Eduardo. Um processo para chamar de seu: nota sobre os negócios jurídicos processuais. Portal Migalhas, de 21 de outubro de 2015. Disponível em: https://goo.gl/x 1rCm9. Acesso em outubro de 2020.

TARUFFO, Michele. Una alternativa a las alternativas: modelos de resolución de conflictos. Páginas sobre justiça civil. Marcial Pons, 2009.

TIMM, Luciano Benetti. Direito e economia no Brasil. São Paulo: Atlas, 2012.

WILLIAMSON, Oliver. The Mechanisms of Governance. New York: Oxford University Press, 1996.

YARSHELL, Flavio Luiz. Convenções das partes em matéria processual: ruma a uma nova Era? In: CABRAL, Antônio do Passo; NOGUEIRA, Pedro Henrique. Negócios Processuais. 2. ed. - Salvador: Ed. JusPodivm, 2016.

ZYLBERSZTAJN, Décio; SZTAJN, Rachel. Direito \& Economia. Rio de Janeiro: Elsevier, 2005.

Submissão: 08 de novembro de 2020

Aceite: 31 de março de 2021 
Autoria:

Marcus Paulo Roder mp.roder@gmail.com

Advogado. Mestrando em Direito no Programa de Pós-Graduação da Universidade Federal do Paraná (PPGD/UFPR).

Kirstin Elise Richter Vieira kirstin@ufpr.br

Graduanda em Direito pela Universidade Federal do Paraná (UFPR).

\section{Como citar este documento:}

RODER, Marcus Paulo; RICHTER VIEIRA, Kirstin Elise. Negócios processuais em contratos empresariais: uma forma de redução de custos de transação. Revista Eletrônica do CEJUR, v. 2, n. $\quad$ 5, $\quad$ set/dez 2020. doi:http://dx.doi.org/10.5380/cejur.v2i5.77771. 